\title{
How Damaging is Part-time Employment to a Woman's
}

\section{Occupational Prospects?}

\author{
Victoria Prowse $* \dagger \ddagger$
}

\begin{abstract}
This paper investigates the causes of the well documented association between part-time employment and low occupational attainment amongst British women. In particular, the relative importance of structural factors and unobserved heterogeneity to the occupational attainment of women who choose to work part-time is investigated. The results indicate that, depending on observed individual characteristics, structural factors explain between $56 \%$ and $87 \%$ of the difference in the occupational attainment of full-time and part-time workers. The remainder of the difference in the occupational attainment of full-time and part-time workers is attributed to differences in the unobserved characteristics of the two groups of workers.
\end{abstract}

KEY Words: Dynamic labor supply, Heterogeneity, Occupational attainment, Part-time employment.

JEL Classification: C15, C35, C23, J62.

*Address for correspondence: Nuffield College, Oxford, OX1 1NF, UK. Email: victoria.prowse@nuffield.ox.ac.uk. Telephone: +4401865 278560.

${ }^{\dagger}$ This work has been supported by the E.S.R.C, grant number PAT-030-2003-00229.

‡This paper uses data from the National Child Development Survey. This data is held by the UK Data Archive in the form of data sets SN 3148 and SN 4396. See http://www.data-archive.ac.uk for further details. 


\section{Introduction}

In Britain, many women who choose to work part-time, often because they want to combine family responsibilities with employment, are employed in low occupations (see Elliott and Egerton 2001). There has been some debate over the source of this association between parttime employment and low occupational status. Some authors argue that there exist constraints or structural factors which prevent women who work part-time from obtaining jobs in high occupations (see Fagan and O'Reilly 1998, Ginn 1996). Morgan and Knights (1991), for example, suggest that part-time workers may be disadvantaged by employers who regard them as less reliable or less committed than their full-time counterparts. Alternatively, it has been suggested that the difference in the occupational attainment of full-time and part-time workers is due to differences in observed and unobserved characteristics between the two groups of workers (see Hakim 1998). In the former case, the same individual will have worse occupational opportunities if they work part-time than if they work full-time. In contrast, in the latter case, a given individual has equal occupational opportunities in both full-time and part-time employment.

The primary goal of this paper is to separate the causal effect of a woman's choice to work part-time on the woman's occupational outcome from the effects of any observed or unobserved individual level characteristics which are relevant to her occupational success. This is achieved by conducting a joint study of the life course employment and occupational dynamics of a cohort of British women. The dynamic framework allows one to quantify both the contemporaneous and long term consequences of a woman's decision to work part-time, whilst controlling for unobserved individual characteristics.

There are two strands of literature within this area. The first focuses on individuals' occupational outcomes, given their employment histories. Particular attention has been paid to the importance of continuous full-time employment for obtaining favorable occupational 
outcomes (see, for example, Martin and Roberts 1984, McRae 1993, Stewart and Greenhalgh 1984). The second strand of literature is concerned with modelling employment dynamics and temporal dependence in employment behavior (see Dex, Joshi and Macran 1999, Heckman and Borjas 1980, Hyslop 1999). The primary challenge within this area is to correctly distinguish between true state dependence and spurious state dependence. According to Heckman (1981), true state dependence occurs when an individual's behavior at time $t$ changes preferences, prices or constraints which are relevant to their future behavior. For example, if an individual is employed at time $t$ this might increase their stock of human capital, which in turn increases their wage and thus probability that they are employed at time $t+1$ (see Mincer and Polachek 1974). In contrast, spurious state dependence is due entirely to persistent unobserved individual specific heterogeneity.

This paper draws on both of these areas by jointly modelling intertemporal employment and occupational outcomes. Employment outcomes, taken to be either full-time employment, parttime employment or non-employment, are allowed to depended on the individual's employment history, and also on their occupational history. Similarly, occupational outcomes are allowed to depend on the individual's employment and occupational history. The possibility of a causal link between part-time employment and occupational attainment is permitted by including an individual's current employment status as a determinant of their current occupational outcome.

In order to separate the causal effect of a woman's employment decision from the effects of her individual characteristics on her occupational outcome one must obviously condition on observed individual characteristics. Also, as in the employment dynamics literature, it is important to control for unobserved individual characteristics. Suppose that there are unobservables which positively affect both an individual's likelihood of full-time employment and their likelihood of obtaining a favorable occupational outcome. Ignoring this correlation 
between the unobservables in the employment and occupational processes will lead one to overstate the effect which working full-time has on the probability of obtaining a favorable occupational outcome. Consequently, ignoring this correlation will lead one to overstate the importance of structural factors in explaining the low occupational status of women in parttime employment. In the model presented below, the specification is sufficiently general so as to allow one to distinguish the causal effect of a woman's employment choice from the effects of her observed and unobserved characteristics.

The model is estimated using data on a cohort of British women taken from waves 3-6 of the National Child Development Study (NCDS). The results indicate that the poor occupational attainment of women in part-time employment as compared to their full-time counterparts, is, in a large part, due to structural impediments to part-time workers obtaining jobs in high occupations. Specifically, depending on individual characteristics, structural factors explain between $56 \%$ and $87 \%$ of the difference in the occupational attainment of full-time and part-time workers.

This paper proceeds as follows. Section 2 discusses the NCDS. Using a sample from the NCDS, the employment and occupational behavior of women between the time at which they left full-time education and age 42 is investigated. For completeness, the behavior of women is compared to the behavior of a corresponding sample of men, also taken from the NCDS. A comparison of some observable characteristics of women in full-time and part-time employment reveals substantial differences between the two groups of women. Section 3 introduces the empirical framework, which is designed to allow one to separate the effect of a woman's employment behavior from the effects of her observed and unobserved characteristics on her occupational outcome. Section 4 details the results, and Section 5 concludes. An appendix contains further particulars about the sample. 


\section{Data and Descriptive Analysis}

The relationship between employment and occupational outcomes is examined using data from the NCDS. The NCDS is a cohort study of all individuals who were born between $3^{\text {rd }}$ and $9^{\text {th }}$ March 1958, and who were resident in England, Scotland or Wales. The initial survey covered $73 \%$ of the target population. Attempts to re-survey the members of this birth cohort were undertaken in 1965, 1969, 1974, 1981 and 1999-2000. Amongst other topics, the survey covers the employment and occupational behavior of the sample members up to the age of 41-42 years, as well as the individuals' educational, fertility and relationship histories. The sample used here consists of all individuals who were still in the study at age 41-42 years, and who provided the required information. For the purpose of this application, employment and occupational behavior is traced on an annual basis from the time at which the individual first left full-time education. Individuals who, at any time during the survey, were long term sick or retired are excluded, as are individuals who returned to full-time education. This sample consists of 6648 individuals and 162446 person-wave observations. 3356 of the individuals in this sample are women, corresponding to 84527 person-wave observations for women.

For the purpose of this paper, only high and low occupations are distinguished. Occupations are classified on the basis of their coding in the 1990 Standard Occupational Classification $(\mathrm{SOC} 90)^{1}$. The SOC90 distinguishes nine major groups of occupations: 1) Managers and administrators; 2) Professional occupations; 3) Associate professional and technical occupations; 4) Clerical and secretarial occupations; 5) Craft and related occupations; 6) Personal and protective service occupations; 7) Sales occupations; 8) Plant and machine operatives; 9) Other occupations. In this study, occupations in major groups 1-3 are defined as high occupations, and occupations in major groups 4-9 are defined as low occupations. Of course, a finer classification

\footnotetext{
${ }^{1}$ The SOC90 is described in detail in Standard Occupational Classification: Volume 1 (1990).
} 
of occupations could be used. However, this binary classification is sufficient to allow an investigation of the relationship between employment and occupational outcomes.

Retrospective information on hours of work is coarse. Specifically, individuals were asked to record only whether a job was full-time or part-time. Actual hours of work were not recorded. A job is defined as full-time if usual weekly hours of work are 30 or above, and part-time if usual weekly hours of work lie between zero and 30. Individuals who were not employed were asked to record the nature of their non-employment i.e. unemployment, family care, government training scheme or another reason. For the purpose of this study, no distinction is made between the different forms of non-employment.

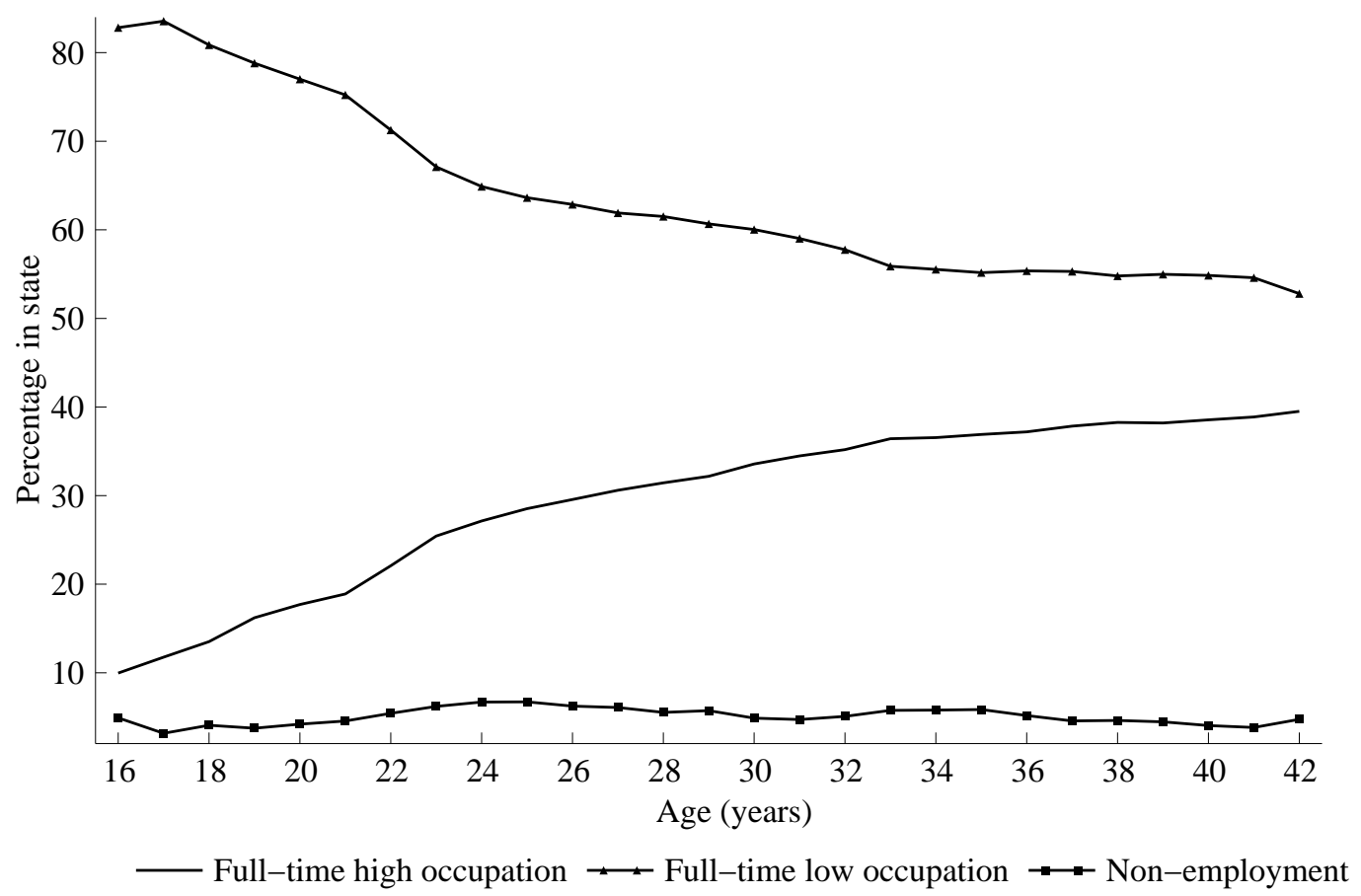

Figure 1: Life course employment and occupational behavior of men.

Figures (1) and (2) show the employment and occupational behavior of men and women between the ages of 16 and 42 years. Men in part-time employment have been excluded due to their small number throughout the period being studied. The proportion of men in non- 


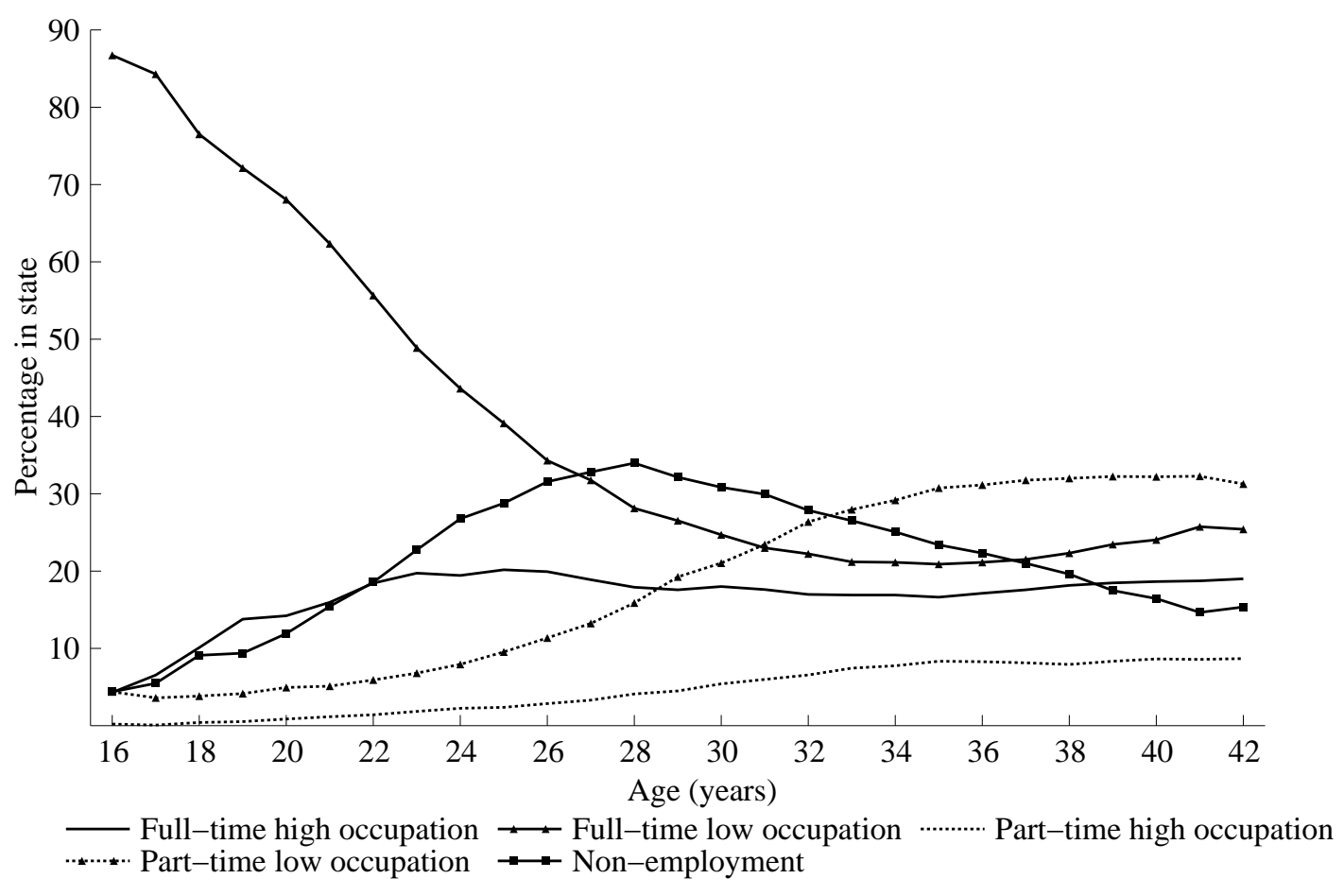

Figure 2: Life course employment and occupational behavior of women.

employment remained at around 5\% throughout the period of the study. Amongst men in full-time employment, the proportion who were in high occupations gradually increased from $12 \%$ at age 16 to $39 \%$ by age 42 . Part of this increase was due to men leaving university and entering the labor market. However, even beyond age 24, when the vast majority of individuals had left full-time education, the proportion of men who were working in high occupations was increasing. This indicates some upwards occupational mobility amongst men.

At age 16, the proportions of women in high and low occupations were very similar to those of men. Also, as for men, at age 16 very few women were working part-time. However, over sample period, the employment and occupational patterns of men and women differed greatly. In particular, the proportion of women in non-employment, which includes women engaged in family care, increased sharply between the ages of 20 and 30 years. In contrast to men, the proportion of women working part-time gradually increased over the sample period, and by age 
42 years almost $50 \%$ of women were working part-time.

Whereas men experienced upwards occupational mobility over the sample period, the same is not true of women. While the proportion of women in full-time, low occupation jobs fell sharply between the ages of 20 and 30 years, there was not a corresponding increase in the proportion of women working in high occupation jobs, either full-time or part-time. Instead, the proportions of women in part-time low occupation jobs and non-employment increased. Beyond age 30, the proportion of women in non-employment started to fall, presumably due to women returning to the labor market as their children became older. It appears that many of these women returned to work in a part-time capacity. Moreover, while there was some increase in the proportion of women in part-time, high occupation jobs, most of the increase in part-time employment took the form of low occupation jobs. Thus, at age 42 years $22 \%$ of women working part-time were employed in high occupations, while $43 \%$ of women working full-time were employed in high occupations.

As noted in the introduction, one potential source of the relatively low occupational attainment of women in part-time employment is differences in observed characteristics between full-time and part-time workers. Table 1 shows that there are substantial differences in observed characteristics between full-time and part-time workers, and between individuals working in high and low occupations. The observed characteristics under consideration consist of age, several measures of education, household structure variables and individuals' employment and occupational outcomes in the previous year and two years previously. Specifically, education is measured by the age at which the individual left full-time education (AGE0), whether or not the individual has a degree or professional qualifications (DEGREE), and whether or not the individual has any technical qualifications of a sufficient standard (TECHQUAL). Household structure is measured by the number of children aged 0-4 years, 5-11 years and 12-15 years 
How Damaging is Part-time Employment to a Woman's Occupational Prospects?

\begin{tabular}{|c|c|c|c|c|c|c|}
\hline \multirow{3}{*}{ VARIABLE } & \multicolumn{3}{|c|}{ FULL-TIME WORKERS } & \multicolumn{3}{|c|}{ PART-TIME WORKERS } \\
\hline & ALL & HIGH & LOW & ALL & HIGH & LOW \\
\hline & & OCCUPATION & OCCUPATION & & OCCUPATION & OCCUPATION \\
\hline AGE & 27.70 & 30.41 & 26.43 & 34.03 & 34.22 & 33.98 \\
\hline AGE0 & 17.69 & 18.77 & 17.18 & 17.52 & 18.81 & 17.19 \\
\hline DEGREE & 0.05 & 0.13 & 0.01 & 0.05 & 0.18 & 0.02 \\
\hline TECHQUAL & 0.02 & 0.03 & 0.01 & 0.01 & 0.02 & 0.01 \\
\hline CHILD1215 & 0.13 & 0.14 & 0.12 & 0.45 & 0.34 & 0.47 \\
\hline CHILD511 & 0.16 & 0.21 & 0.14 & 0.76 & 0.72 & 0.77 \\
\hline CHILD04 & 0.13 & 0.16 & 0.11 & 0.43 & 0.55 & 0.40 \\
\hline COHABIT & 0.55 & 0.63 & 0.52 & 0.89 & 0.91 & 0.89 \\
\hline $\mathrm{FTH}_{i, t-1}$ & 0.29 & 0.87 & 0.01 & 0.02 & 0.05 & 0.01 \\
\hline $\mathrm{FTH}_{i, t-2}$ & 0.26 & 0.76 & 0.02 & 0.03 & 0.09 & 0.01 \\
\hline $\mathrm{FTL}_{i, t-1}$ & 0.60 & 0.06 & 0.86 & 0.04 & 0.02 & 0.04 \\
\hline $\mathrm{FTL}_{i, t-2}$ & 0.54 & 0.09 & 0.75 & 0.07 & 0.05 & 0.08 \\
\hline $\mathrm{PTH}_{i, t-1}$ & 0.00 & 0.01 & 0.00 & 0.17 & 0.82 & 0.01 \\
\hline $\mathrm{PTH}_{i, t-2}$ & 0.01 & 0.02 & 0.00 & 0.15 & 0.68 & 0.01 \\
\hline $\mathrm{PTL}_{i, t-1}$ & 0.02 & 0.01 & 0.02 & 0.66 & 0.03 & 0.82 \\
\hline $\mathrm{PTL}_{i, t-2}$ & 0.03 & 0.02 & 0.03 & 0.57 & 0.05 & 0.70 \\
\hline
\end{tabular}

Table 1: Sample means of women's observed characteristics according to employment-occupation state.

(CHILD04, CHILD511 and CHILD1215), and an indicator of whether or not the women is cohabiting (COHABIT). Individual $i$ 's employment behavior at time $j$ is described by four indicator variables: $\mathrm{FTH}_{i, j}, \mathrm{FTL}_{i, j}, \mathrm{PTH}_{i, j}$ and $\mathrm{PTL}_{i, j}$, corresponding to full-time employment in a high or a low occupation, and part-time employment in a high or a low occupation respectively. More detailed definitions of these variables are given in Table 6 in the Appendix. The sample means of all of the variables are shown in Table 7, also in the Appendix.

Table 1 reveals that women in full-time employment tend to be younger than women in part- 
time employment. Amongst women in either full-time employment or part-time employment, women in high occupations tend to be slightly older and more highly educated than women in low occupations. Women in part-time employment have, on average, more children than women in full-time employment. Also, women in part-time employment are more likely to be cohabiting than women in full-time employment. Past employment and occupational behavior is highly correlated with current employment and occupational behavior. For example, $87 \%$ of women in full-time employment in a high occupation were in the same state a year ago, and $76 \%$ were in the same state 2 years previously. Similar figures apply to the other employmentoccupation states.

\section{Empirical Framework}

In this section an empirical framework for jointly analyzing employment and occupational outcomes is developed. This framework allows one to distinguish between the effect of an individual's employment choice and the effects of their observed and unobserved characteristics on their occupational outcome. In particular, this framework allows one to determine if a woman's choice to work part-time is truly damaging to her occupational prospects, or whether women who choose to work part-time are in some way different from women who choose to work full-time.

First, the process determining employment outcomes is specified. Given their employment and occupational history, and individual characteristics, each individual determines their desired hours of work, $h_{i, t}^{*}$. Here and in all that follows $i=1, \ldots, N$ indexes the individuals and $t=\tau_{i}, \ldots, T$ denotes the time of the observation, where $\tau_{i}$ corresponds to the time at which individual $i$ left full-time education. Desired hours of work are assumed to conform to the 
following equation:

$$
\begin{aligned}
h_{i, t}^{*}= & \beta X_{i, t}+\gamma_{F T, H} \mathrm{FTH}_{i, t-1}+\gamma_{F T, L} \mathrm{FTL}_{i, t-1}+\gamma_{P T, H} \mathrm{PTH}_{i, t-1} \\
& +\gamma_{P T, L} \mathrm{PTL}_{i, t-1}+\Gamma_{F T, H} \mathrm{FTH}_{i, t-2}+\Gamma_{F T, L} \mathrm{FTL}_{i, t-2} \\
& +\Gamma_{P T, H} \mathrm{PTH}_{i, t-2}+\Gamma_{P T, L} \mathrm{PTL}_{i, t-2}+\nu_{i t} \\
= & g_{i, t}+\nu_{i, t} .
\end{aligned}
$$

In the above, $\beta$ is a 1 by $l$ vector of unknown parameters, and $\gamma_{F T, H}, \gamma_{F T, L}, \gamma_{P T, H}, \gamma_{P T, L}$, $\Gamma_{F T, H}, \Gamma_{F T, L}, \Gamma_{P T, H}$ and $\Gamma_{P T, L}$ are unknown scalar parameters. This specifications allows an individual's employment and occupational behavior in the pervious year and two years perviously to affect their current desired hours. $X_{i, t}$ is a $l$ by 1 vector of observed individual characteristics which are determinants of desired hours of work. Given that neither the wage nor non-labor income are observed, $X_{i, t}$ also includes any additional variables which are proxies for either the wage or non-labor income. $\nu_{i, t}$ is an individual specific error term, representing the unobserved component of individual $i$ 's preference over desired hours of work at time $t$.

Observed employment behavior is related to desired hours of work as follows: if $h_{i, t}^{*}>\bar{\eta}$ full-time employment is observed, if $\underline{\eta}<h_{i, t}^{*} \leq \bar{\eta}$ part-time employment is observed, and if $h_{i, t}^{*} \leq \underline{\eta}$ non-employment is observed. Here, $\underline{\eta}$ is an unknown constant, and $\bar{\eta}$ is allowed to vary with the individual's employment behavior in the previous period. Specifically, $\bar{\eta}=\underline{\eta}+$ $\kappa_{N} \mathrm{~N}_{i, t-1}+\kappa_{P T} \mathrm{PT}_{i, t-1}+\kappa_{F T} \mathrm{FT}_{i, t-1}$, where $\kappa_{N}, \kappa_{P T}$ and $\kappa_{F T}$ are unknown positive constants, and $\mathrm{N}_{i, t-1}, \mathrm{PT}_{i, t-1}$ and $\mathrm{FT}_{i, t-1}$ are indictors of non-employment, part-time employment and full-time employment for individual $i$ at time $t-1 .^{2,3}$

This specification of observed employment behavior allows current employment behavior

\footnotetext{
${ }^{2}$ The relationship between desired hours and actual hours is left unspecified; all that is required is that actual hours correspond to full-time employment when desired hours exceed $\bar{\eta}$, and part-time employment when desired hours lie between $\underline{\eta}$ and $\bar{\eta}$.

${ }^{3}$ Given this specification, it is not possible to identify an intercept in Equation (1).
} 
to depend on previous employment behavior through two channels. Firstly, past employment behavior can affect current desired hours, and secondly, past employment behavior can affect the threshold level of desired hours at which the individual switches from part-time employment to full-time employment. This is an extension of the standard ordered choice model where the thresholds at which individuals change their behavior are constant across both time and individuals. ${ }^{4}$ Thus this specification allows greater flexibility in the nature of true state dependence in employment behavior than a standard ordered choice model. ${ }^{5}$

The process determining occupational outcomes is specified such that the low occupational attainment of part-time workers can be attributed to either observed or unobserved differences between part-time and full-time workers or to structural impediments to part-time workers obtaining jobs in high occupations. Let $y_{i, t}^{*}$ be a latent variable which determines the occupational outcome of individual $i$ at time $t$. The individual works in high occupation if $y_{i, t}^{*}>0$, and works in a low occupations if $y_{i, t}^{*} \leq 0$. The latent variable $y_{i, t}^{*}$ is related to individual characteristics as follows:

$$
\begin{aligned}
y_{i, t}^{*}= & \theta \mathrm{FT}_{i, t}+\alpha Z_{i, t}+\delta_{F T, H} \mathrm{FTH}_{i, t-1}+\delta_{F T, L} \mathrm{FTL}_{i, t-1}+\delta_{P T, H} \mathrm{PTH}_{i, t-1} \\
& +\delta_{P T, L} \mathrm{PTL}_{i, t-1}+\Delta_{F T, H} \mathrm{FTH}_{i, t-2}+\Delta_{F T, L} \mathrm{FTL}_{i, t-2} \\
& +\Delta_{P T, H} \mathrm{PTH}_{i, t-2}+\Delta_{P T, L} \mathrm{PTL}_{i, t-2}+\epsilon_{i t} \\
= & d_{i, t}+\epsilon_{i t}
\end{aligned}
$$

In the above, $\alpha$ is a 1 by $k$ vector of unknown parameters, and $\theta, \delta_{F T, H}, \delta_{F T, L}, \delta_{P T, H}, \delta_{P T, L}$, $\Delta_{F T, H}, \Delta_{F T, L}, \Delta_{P T, H}$ and $\Delta_{P T, L}$ are unknown scalar parameters. $Z_{i, t}$ is a $k$ by 1 vector of observed individual characteristics which influence the individual's occupational outcome at time $t . \quad Z_{i, t}$ is constructed such that Equation (3) has an intercept. This specification allows

\footnotetext{
${ }^{4}$ Pudney and Shields (2000) estimate a similarly extended ordered choice model.

${ }^{5}$ Experimentation with alternative specifications revealed that a standard ordered choice model under predicts the observed state dependence in employment behavior. The extended specification, however, is able to accurately predict the observed state dependence in employment behavior.
} 
an individual's employment and occupational outcomes in each of the two proceeding years to affect their occupational outcome at time $t . \epsilon_{i, t}$ is an individual specific error term which captures any unobserved individual specific factors which influence an individual's likelihood of working in a high occupation at time $t . \epsilon_{i, t}$ includes factors such as unobserved ability and motivation and also factors reflecting the woman's occupational ambitions. Thus, this specification allows a woman to have an unobserved preference for jobs in low occupations. This could occur if, for example, jobs in low occupations offer greater flexibility or are less stressful than jobs in high occupations.

A positive value of $\theta$ implies structural impediments to part-time workers obtaining jobs in high occupations. However, if $\theta$ is equal to zero, occupational success is independent of an individual's current employment choice. In the latter case, the difference in the occupational success of full-time and part-time workers is due to observed or unobserved differences in the characteristics of the two groups of workers.

\begin{tabular}{c|cc}
\hline \hline & HIGH OCCUPATION & LOW OCCUPATION \\
\hline FULL-TIME EMPLOYMENT & $-d_{i, t}<\epsilon_{i, t}<\infty$ & $-\infty<\epsilon_{i, t} \leq-d_{i, t}$ \\
& $\bar{\eta}-g_{i, t}<\nu_{i, t}<\infty$ & $\bar{\eta}-g_{i, t}<\nu_{i, t}<\infty$ \\
\hline PART-TIME EMPLOYMENT & $-d_{i, t}<\epsilon_{i, t}<\infty$ & $-\infty<\epsilon_{i, t} \leq-d_{i, t}$ \\
& $\underline{\eta}-g_{i, t}<\nu_{i, t} \leq \bar{\eta}-g_{i, t}$ & $\underline{\eta}-g_{i, t}<\nu_{i, t} \leq \bar{\eta}-g_{i, t}$ \\
\hline NON-EMPLOYMENT & \multicolumn{2}{|c}{$-\infty<\epsilon_{i, t}<\infty$} \\
& & $-\infty<\nu_{i, t} \leq \underline{\eta}-g_{i, t}$ \\
\hline
\end{tabular}

Table 2: Possible employment-occupation states.

At each time period, an individual falls into one of five possible employment-occupation states. For reference, these outcomes are illustrated in Table 2.

In general, $\epsilon_{i, t}$ and $\nu_{i, t}$ will be correlated over time, due to the presence of persistent unobserved individual characteristics such as motivation or ability. Also, if the same unobserved 
individual specific factors affect the availability of jobs in high occupations at time $t$ and desired hours of work at time $t$ there will be a non-zero contemporaneous correlation between $\epsilon_{i, t}$ and $\nu_{i, t}$. As discussed above, controlling for intertemporally correlated unobservables is crucial to correctly determining the source of association between part-time employment and low occupational status.

With the importance of adequately controlling for intertemporal correlations in unobservables in mind, the following distributional assumptions are made. The vector $\varepsilon_{i, t}=\left(\nu_{i, t}, \epsilon_{i, t}\right)^{\prime}$ is assumed to be normally distributed with mean $m=\left(\pi_{1} \bar{X}_{i}, \pi_{2} \bar{Z}_{i}\right)^{\prime}$, where $\bar{X}_{i}$ and $\bar{Z}_{i}$ are the average over the sample period of the time varying elements of $X_{i, t}$ and $Z_{i, t}$ respectively, and $\pi_{1}$ and $\pi_{2}$ are suitably dimensioned vectors of unknown parameters. Including the sample means of the time varying variables, as suggested by Chamberlain (1984), allows individuals' unobserved preferences to be correlated with their observed characteristics. This allows, for example, education and fertility to be endogenous. Denote $\nu_{i, t}$ and $\epsilon_{i, t}$ net of their respective means by $\check{\nu}_{i, t}$ and $\check{\epsilon}_{i, t}$. The variances of both $\check{\nu}_{i, t}$ and $\check{\epsilon}_{i, t}$ are normalized to one. Denote the covariance between $\check{\nu}_{i, t}$ and $\check{\epsilon}_{i, t}$ by $\sigma_{\nu \epsilon}$. Let $\check{\nu}_{i, t}=\mu_{1, i}+\widetilde{\nu}_{i, t}$ and $\check{\epsilon}_{i, t}=\mu_{2,1}+\widetilde{\epsilon}_{i, t}$. Here, $\mu_{1, i}$ and $\mu_{2, i}$ represent the time invariant elements of $\check{\nu}_{i, t}$ and $\check{\epsilon}_{i, t}$. Assume $\left(\mu_{1, i}, \mu_{2, i}\right)^{\prime} \sim N(0, \Sigma)$. $\widetilde{\nu}_{i, t}$ and $\widetilde{\epsilon}_{i, t}$ are the time varying elements of $\check{\nu}_{i, t}$ and $\check{\epsilon}_{i, t}$. Specifically, $\widetilde{\nu}_{i, t}$ and $\widetilde{\epsilon}_{i, t}$ are assumed to be autocorrelated. Thus $\widetilde{\nu}_{i, t}=\rho_{1} \widetilde{\nu}_{i, t}+\xi_{i, t}$ and $\widetilde{\epsilon}_{i, t}=\rho_{2} \widetilde{\epsilon}_{i, t}+\psi_{i, t}$, where $\xi_{i, t} \sim N\left(0,1-\rho_{1}^{2}\right)$, $\psi_{i, t} \sim N\left(0,1-\rho_{2}^{2}\right)$. Further assume $\mathrm{E}\left[\xi_{i, s} \psi_{i, t}\right]=\mathrm{E}\left[\xi_{i, s} \xi_{i, t}\right]=\mathrm{E}\left[\psi_{i, s} \psi_{i, t}\right]=0$ for all $s$ and $t$. These distributional assumptions allow both time invariant and autocorrelated unobservables, and permit contemporaneous and intertemporal correlations between the unobservables in the employment and occupation equations.

Define $\varepsilon_{i}$ as $\varepsilon_{i, t}$ stacked over $t$. The above assumptions imply that $\varepsilon_{i} \sim N(m, \Omega)$ where $m$ is as defined above and $\Omega$ has a components of variance structure. Individual likelihood contri- 
butions take the form $L_{i}=P\left(a_{i} \leq \varepsilon_{i} \leq b_{i}\right)$, where the $2 T$ by 1 dimensional vectors $a_{i}$ and $b_{i}$ are composed of the appropriate elements from Table 2. The individual likelihood contributions are evaluated using the GHK simulator, see Borsch-Supan and Hajivassiliou (1993), Geweke (1991), Hajivassiliou and Rudd (1994) and Hajivassiliou, McFadden and Ruud (1996). Let $R$ be the number of simulations used when evaluating the likelihood. The Maximum Simulated Likelihood Estimates, found by maximizing the simulated likelihood, are consistent if $N \rightarrow \infty$ as $R \rightarrow \infty$, and are asymptotically equivalent to the corresponding maximum likelihood estimates if $R$ increases at a rate faster then $N^{1 / 2}{ }^{6}$

\section{Results}

In the implementation of the above model, the vector $X_{i, t}$, which enters the equation determining desired hours of work, is assumed to consist of a set of biennial time dummies and the education and household structure variables described above. To ensure identification of the model, $X_{i, t}$ must include at least one variable which is excluded from $Z_{i, t} \cdot{ }^{7}$ Here, the household structure variables are included in $X_{i, t}$, but are excluded from $Z_{i, t}$. Thus, it is assumed that, conditional on whether or not the individual works full-time, the time dummies, the individual's employment and occupational history and the individual's other included characteristics, the household structure variables do not affect the probability that the individual works in a high

\footnotetext{
${ }^{6}$ When estimating the model, the likelihood was simulated using 30 replications of the GHK simulator. The possibility of simulation bias was investigated by repeating the estimation with $R=50$. This revealed only marginal changes in the estimated parameters, thus suggesting that the results are not subject to simulation bias.

${ }^{7}$ Formally, the model is identified without this exclusion restriction. However, in the absence of an exclusion restriction, identification relies on the non-linearity of the functional form. Moreover, simulations showed identification to be fragile in the absence of an exclusion restriction.
} 
occupation. $^{8,9}$

The results are presented in Table 3. First, the estimates of the parameters of the employment equation are discussed. Relative to non-employment, being in any employmentoccupation state in either the previous year or two years previously significantly increases an individual's desired hours of work in the current year. Thus, there is true state dependence in employment behavior. Unsurprisingly, an individual's employment and occupational experiences in the last year exert a larger influence on their current desired hours of work than their behavior two years ago. Being in part-time employment in the previous year substantially increases an individual's current desired hours of work. In fact, ceteris paribus, an individual who worked part-time in the previous year has slightly higher desired hours than an individual who worked full-time in the pervious year. However, this does not translate into a higher probability of full-time employment for an individual who worked part-time than for an individual who worked full-time. This is because the threshold level of desired hours at which an individual switches from part-time employment to full-time employment is strongly dependent on the individual's employment behavior in the previous year: individuals who were in part-time employment in the previous year have a significantly higher threshold over which desired hours must lie in order for them to work full-time. This suggests that much of the observed persistence in employment behavior is due to thresholds which are dependent on individuals' past employment behavior, rather than being due to past employment behavior influencing desired hours directly.

\footnotetext{
${ }^{8}$ The time varying elements of $X_{i, t}$ consist of DEGREE and TECHQUAL, and the household structure variables, while the time varying elements of $Z_{i, t}$ are DEGREE and TECHQUAL. The individual specific sample means of these variables are included in the model, as described in Section 3.

${ }^{9} \mathrm{AGE} 0$, the age at which the individual left full-time education, has been scaled to have zero mean and unit variance. This improves the numerical performance of the estimator.
} 


\begin{tabular}{|c|c|c|}
\hline VARIABLE & EMPLOYMENT EQUATION & OCCUPATION EQUATION \\
\hline FT & - & $\begin{array}{c}0.39 \\
(0.03)\end{array}$ \\
\hline AGE0 & $\begin{array}{l}0.02 \\
(0.01)\end{array}$ & $\begin{array}{l}0.30 \\
(0.01)\end{array}$ \\
\hline DEGREE & $\begin{array}{l}0.02 \\
(0.06)\end{array}$ & $\begin{array}{l}0.13 \\
(0.06)\end{array}$ \\
\hline TECHQUAL & $\begin{array}{l}0.06 \\
(0.09)\end{array}$ & $\begin{array}{l}0.06 \\
(0.10)\end{array}$ \\
\hline CHILD1215 & $\begin{array}{r}-0.11 \\
(0.01)\end{array}$ & - \\
\hline CHILD511 & $\begin{array}{r}-0.19 \\
(0.01)\end{array}$ & - \\
\hline CHILD04 & $\begin{array}{r}-0.61 \\
(0.01)\end{array}$ & - \\
\hline COHABIT & $\begin{array}{r}-0.69 \\
(0.02)\end{array}$ & - \\
\hline $\mathrm{FTH}_{i, t-1}$ & $\begin{array}{l}0.80 \\
(0.04)\end{array}$ & $\begin{array}{l}1.82 \\
(0.06)\end{array}$ \\
\hline $\mathrm{FTH}_{i, t-2}$ & $\begin{array}{l}0.37 \\
(0.03)\end{array}$ & $\begin{array}{l}0.23 \\
(0.05)\end{array}$ \\
\hline $\mathrm{FTL}_{i, t-1}$ & $\begin{array}{l}0.68 \\
(0.03)\end{array}$ & $\begin{array}{r}-0.75 \\
(0.04)\end{array}$ \\
\hline $\mathrm{FTL}_{i, t-2}$ & $\begin{array}{l}0.32 \\
(0.02)\end{array}$ & $\begin{array}{r}-0.10 \\
(0.04)\end{array}$ \\
\hline $\mathrm{PTH}_{i, t-1}$ & $\begin{array}{l}1.53 \\
(0.05)\end{array}$ & $\begin{array}{l}2.07 \\
(0.08)\end{array}$ \\
\hline $\mathrm{PTH}_{i, t-2}$ & $\begin{array}{l}0.17 \\
(0.04)\end{array}$ & $\begin{array}{l}0.27 \\
(0.07)\end{array}$ \\
\hline $\mathrm{PTL}_{i, t-1}$ & $\begin{array}{l}1.41 \\
(0.03)\end{array}$ & $\begin{array}{r}-0.68 \\
(0.05)\end{array}$ \\
\hline $\mathrm{PTL}_{i, t-2}$ & $\begin{array}{l}0.20 \\
(0.02)\end{array}$ & $\begin{array}{r}-0.03 \\
(0.05)\end{array}$ \\
\hline$\overline{\text { DEGREE }}$ & $\begin{array}{l}0.19 \\
(0.08)\end{array}$ & $\begin{array}{l}0.79 \\
(0.09)\end{array}$ \\
\hline$\overline{\text { TECHQUAL }}$ & $\begin{array}{l}0.22 \\
(0.14)\end{array}$ & $\begin{array}{l}0.15 \\
(0.15)\end{array}$ \\
\hline$\overline{\text { CHILD1215 }}$ & $\begin{array}{r}-0.27 \\
(0.09)\end{array}$ & - \\
\hline$\overline{\text { CHILD511 }}$ & $\begin{array}{r}-0.21 \\
(0.13)\end{array}$ & - \\
\hline$\overline{\text { CHILD04 }}$ & $\begin{array}{r}-0.14 \\
(0.12)\end{array}$ & - \\
\hline$\overline{\mathrm{COHABIT}}$ & $\begin{array}{l}0.60 \\
(0.05)\end{array}$ & - \\
\hline INTERCEPT & - & $\begin{array}{r}-1.46 \\
(0.04)\end{array}$ \\
\hline \multicolumn{3}{|c|}{ ANCILLARY PARAMETERS } \\
\hline$\underline{\eta}$ & \multicolumn{2}{|c|}{$\begin{array}{r}-1.00 \\
(0.04)\end{array}$} \\
\hline$\kappa_{N}$ & \multicolumn{2}{|c|}{$\begin{array}{l}0.52 \\
(0.01)\end{array}$} \\
\hline$\kappa_{P}$ & \multicolumn{2}{|c|}{$\begin{array}{l}3.02 \\
(0.03)\end{array}$} \\
\hline$\kappa_{F}$ & \multicolumn{2}{|c|}{$\begin{array}{l}0.21 \\
(0.01)\end{array}$} \\
\hline$c_{1,2}$ & \multicolumn{2}{|c|}{$\begin{array}{l}0.07 \\
(0.01)\end{array}$} \\
\hline$\mu_{1,1}$ & \multicolumn{2}{|c|}{$\begin{array}{l}0.17 \\
(0.01)\end{array}$} \\
\hline$\mu_{1,2}$ & \multicolumn{2}{|c|}{$\begin{array}{l}0.03 \\
(0.01)\end{array}$} \\
\hline$\mu_{2,2}$ & \multicolumn{2}{|c|}{$\begin{array}{l}0.21 \\
(0.02)\end{array}$} \\
\hline$\rho_{1}$ & \multicolumn{2}{|c|}{$\begin{array}{l}0.40 \\
(0.01)\end{array}$} \\
\hline$\rho_{2}$ & \multicolumn{2}{|c|}{$\begin{array}{l}0.00 \\
(0.02)\end{array}$} \\
\hline Log likelihood & \multicolumn{2}{|c|}{-43170.0} \\
\hline
\end{tabular}

Table 3: Results. Standard errors in parenthesis. Estimates of the time dummies have been omitted. 
While technical qualifications do not have a significant effect on desired hours of work, degree level or professional qualifications and the age at which the individual left full-time education both exert significant positive effects on desired hours of work. Children of any age decrease desired hours of work, with the effect being largest for children aged under 5 years. Cohabiting individuals have significantly lower desired hours of work than non-cohabiting individuals. Examining the coefficients on the sample means of the time varying variables reveals that neither qualifications nor fertility are exogenous to individuals' desired hours of work. ${ }^{10}$ In particular, the higher an individual's preference for children the lower their desired hours of work, individuals with a higher preference for cohabiting have, ceteris paribus, higher desired hours of work, and the higher an individual's preference for education the higher their desired hours of work.

Turning to the results for the equation determining occupational outcomes revels that working full-time significantly increases the probability that an individual obtains a job in a high occupation. Thus, even after controlling for observed and unobserved individual characteristics, there is significant evidence of structural impediments to part-time workers obtaining jobs in high occupations.

The higher the age at which the individual left full-time education the higher the probability that they will be working in a high occupation. Degree level or professional qualifications also significantly increase an individual's occupational prospects. However, technical qualifications have no significant effect on an individual's probability of working in a high occupation. Also, the higher an individual's preference for education in the form of degree level or professional qualifications the higher the probability that they are able to obtain a job in a high occu-

\footnotetext{
${ }^{10}$ The Wald test statistic for hypothesis that both DEGREE and TECHQUAL are insignificant in the employment equation is $7.38(0.025)$. The Wald test statistic for hypothesis that all child variables are insignificant in the employment equation is $114.74(0.000)$. p values in parenthesis.
} 
pation. This suggests that it is not only an individual's actual qualifications, but also their overall preference for gaining degree level or professional qualifications which is relevant to their occupational outcome.

Working an a high occupation at time $t-1$, either full-time or part-time, significantly increases the probability that an individual is employed in a high occupation in the current period. Symmetrically, working either full-time or part-time in a low occupation at time $t-1$ significantly reduces the probability that an individual is employed in a high occupation in the current period. Working full-time in a high occupation at time $t-2$ significantly increases an individual's likelihood of obtaining a high occupation job in the current period, while fulltime employment in a low occupation at $t-2$ significantly decreases an individual's current occupational prospects. Irrespective of occupation, part-time employment at $t-2$ does not have a significant effect on an individual's current occupational outcome. Thus while fulltime employment in a low occupation has a long term, detrimental, effect on an individual's occupational prospects, part-time employment in a low occupation does not have a long term scaring effect on an individual's occupational prospects.

There are substantial intratemporal and intertemporal correlations in unobservables. In particular, the results suggest that there is a small amount of time invariant unobserved heterogeneity which affects employment. Also, there is significant positive autocorrelation in the unobservables entering the employment equation. There is some time-invariant heterogeneity which affects occupational outcomes, however, there is no significant autocorrelated element to the unobservables entering the occupation equation. There is a small yet significant amount of time invariant heterogeneity which affects both employment and occupational outcomes. Also, there is a small but significant positive contemporaneous correlation between the unobservables in the employment equation and the unobservables in the occupation equation. 


\begin{tabular}{|c|c|c|c|c|c|c|}
\hline \multirow[b]{2}{*}{ STATE } & \multicolumn{2}{|c|}{ WOMAN $1^{a}$} & \multicolumn{2}{|c|}{ WOMAN $2^{b}$} & \multicolumn{2}{|c|}{ WOMAN $3^{c}$} \\
\hline & BEFORE & AFTER & BEFORE & AFTER & BEFORE & AFTER \\
\hline FTH & 0.11 & 0.12 & 0.28 & 0.29 & 0.54 & 0.55 \\
\hline FTL & 0.47 & 0.47 & 0.50 & 0.49 & 0.05 & 0.05 \\
\hline PTH & 0.02 & 0.05 & 0.02 & 0.05 & 0.20 & 0.22 \\
\hline PTL & 0.26 & 0.24 & 0.15 & 0.12 & 0.05 & 0.03 \\
\hline $\mathrm{N}$ & 0.13 & 0.13 & 0.05 & 0.05 & 0.16 & 0.16 \\
\hline PROPORTION OF FULL-TIMERS & 0.19 & 0.20 & 0.36 & 0.37 & 0.91 & 0.91 \\
\hline \multicolumn{7}{|l|}{ IN HIGH OCCUPATIONS } \\
\hline PROPORTION OF PART-TIMERS & 0.08 & 0.17 & 0.14 & 0.29 & 0.81 & 0.90 \\
\hline \multicolumn{7}{|l|}{ IN HIGH OCCUPATIONS } \\
\hline$\%$ OF GAP DUE TO & \multicolumn{2}{|c|}{$67 \%$} & \multicolumn{2}{|c|}{$56 \%$} & \multicolumn{2}{|c|}{$87 \%$} \\
\hline STRUCTURAL FACTORS & & & & & & \\
\hline
\end{tabular}

${ }^{a}$ Woman 1 left full-time education at age 16 years, never obtained any degree level or professional or technical qualification, was cohabiting from age 18 years, and had one child at age 19 years.

${ }^{b}$ Woman 2 left full-time education at age 18 years and obtained a technical qualification at age 21 years. Woman 2 did not cohabit or have any children.

${ }^{c}$ Woman 3 left full-time education at age 21 years with a degree level qualification, was cohabiting from age 27 years, and had one child at age 29 years and a second child at age 31 years.

Table 4: Expected employment and occupational outcomes of three women between leaving full-time education and age 42 years, before and after the removal of structural impediments to part-time workers obtaining jobs in high occupations.

The relative importance of structural factors and unobserved individual characteristics to the occupational attainment of part-time workers is now investigated further. Table 4 shows the effects of removing structural impediments to part-time workers obtaining high occupational outcomes for three women with different observed characteristics. Before the removal of structural factors which prevent part-time workers from obtaining high occupational outcomes all three women have a substantially higher probability of working in a high occupation if they 


\begin{tabular}{|c|c|c|c|c|c|c|}
\hline \multirow[b]{2}{*}{ STATE } & \multicolumn{2}{|c|}{ AGE 20 YEARS } & \multicolumn{2}{|c|}{ AGE 30 YEARS } & \multicolumn{2}{|c|}{ AGE 40 YEARS } \\
\hline & BEFORE & AFTER & BEFORE & AFTER & BEFORE & AFTER \\
\hline FTH & 0.15 & 0.15 & 0.16 & 0.17 & 0.17 & 0.19 \\
\hline FTL & 0.62 & 0.62 & 0.26 & 0.26 & 0.32 & 0.31 \\
\hline PTH & 0.01 & 0.03 & 0.05 & 0.09 & 0.07 & 0.11 \\
\hline PTL & 0.14 & 0.12 & 0.22 & 0.19 & 0.28 & 0.23 \\
\hline $\mathrm{N}$ & 0.08 & 0.08 & 0.30 & 0.29 & 0.16 & 0.16 \\
\hline PROPORTION OF FULL-TIMERS & 0.19 & 0.19 & 0.38 & 0.40 & 0.35 & 0.39 \\
\hline \multicolumn{7}{|l|}{ IN HIGH OCCUPATIONS } \\
\hline PROPORTION OF PART-TIMERS & 0.09 & 0.17 & 0.19 & 0.31 & 0.19 & 0.33 \\
\hline \multicolumn{7}{|l|}{ IN HIGH OCCUPATIONS } \\
\hline$\%$ OF GAP DUE TO & \multicolumn{2}{|c|}{$74 \%$} & \multicolumn{2}{|c|}{$55 \%$} & \multicolumn{2}{|c|}{$65 \%$} \\
\hline STRUCTURAL FACTORS & & & & & & \\
\hline
\end{tabular}

Table 5: Expected employment and occupational outcomes of the women in the sample at ages 20, 30 and 40 years, before and after the removal of structural impediments to part-time workers obtaining jobs in high occupations.

work full-time than if they work part-time. The difference in smallest for woman 3 , the most highly qualified of the three women under consideration, and largest for woman 2 , the woman with the highest probability of employment.

Once part-time workers are given the same occupational opportunities as full-time workers, the difference in the occupational success of part-time and full-time workers narrows considerably. For example, for poorly qualified woman 1 the probability of working in a high occupation if in part-time employment increases from 0.08 to 0.17 when part-time workers are given the same occupational opportunities as full-time workers. Thus amongst women with the observable characteristics of woman 1, structural factors explain $67 \%$ of the lower occupation attainment of part-time workers relative to full-time workers. The residual, $33 \%$ of the 
difference in the occupational attainment of full-time and part-time workers, is thus due to unobserved individual characteristics. There is some variation in the importance of structural factors to the occupational attainment of part-time workers across women with different observed characteristics: amongst woman with the observed characteristics of woman 2 structural factors explain $56 \%$ of the lower occupational attainment of part-time workers relative to fulltime workers, whereas amongst woman with the observed characteristics of woman 3 structural factors explain $87 \%$ of the difference in the occupational attainment of full-time and part-time workers.

Table 5 extrapolates the above analysis to include all of the women who are in the sample. Across the women in the sample, structural factors are an important determinant of the relatively low occupational attainment of part-time workers. Specifically, structural factors explain $74 \%, 55 \%$ and $65 \%$ of the difference in the occupational attainment of full-time and part-time workers at ages 20,30 and 40 years respectively. Given that these figures have been constructed by averaging across individuals with different observed characteristics, the residual is now due to a combination of observed and unobserved individual characteristics.

\section{Conclusion}

This paper sheds some light on the source of the low occupational attainment of women in part-time employment. In particular, the relative contributions of structural factors, such as employers' policies, and unobserved heterogeneity to the low occupational attainment of women in part-time employment have been analyzed.

The above results show that the majority of difference in the occupational attainment of full-time and part-time workers is due to structural factors: removing structural impediments to part-time workers obtaining jobs in high occupations would eliminate most of the difference 
in the occupational attainment of part-time and full-time workers. The relative importance of structural factors and unobserved heterogeneity to explaining the difference in the occupational attainment of full-time and part-time workers varies with observed individual characteristics. Unobserved heterogeneity is least important amongst highly educated women, who have a relatively high probability of obtaining a job in a high occupation irrespective of whether they work full-time or part-time. However, for women with a high probability of employment, either full-time or part-time, unobserved heterogeneity is more important. Indeed for such women, unobserved difference explain almost half of the difference in the occupational attainment of full-time and part-time workers.

Give the available data, it is not possible to determine the exact nature of the unobservables which jointly affect employment and occupational outcomes. It could, for example, be the case that an individual choosing to work part-time also has unobserved traits which reduce the likelihood that they will be able to obtain a job in a high occupation. Alternatively, an individual choosing to work part-time might have a preference for jobs in low occupations over jobs in high occupations because jobs in low occupations are more flexible or less stressful than jobs in high occupations.

The findings in this paper are relevant to understanding other empirical regularities relating to the British labor market. For example, the wage differential between male and female workers is acknowledged as being partly due to the lower wages of part-time workers, who are predominantly female. The low wages of part-time workers have, in turn, been linked to the poor occupational status of part-time workers (see Greenhalgh 1980, Miller 1987). The above results suggest that in the absence of structural impediments to part-time workers entering high occupations, a higher proportions of part-time workers would be employed in high occupations. In consequence, one would expect the wage differential between part-time workers and full-time 
workers, and between men and women, to decrease.

Given the nature of the data set used here, this study is necessarily somewhat historic. Recent legislation, for example The Employment Relations Act 1999 and The Part-time Workers (Prevention of Less Favourable Treatment) Regulations 2000, may well have reduced the disadvantage faced by part-time workers. Indeed, once sufficient data exists, it will be possible to examine the impact of recent legislation on the occupational attainment of part-time workers. 


\section{References}

Borsch-Supan, A and V. Hajivassiliou. 1993. "Smooth Unbiased Multivariate Probability Simulators for Maximum Likelihood Estimation of Limited Dependent Variable Models." Journal of econometrics 58:347-368.

Chamberlain, G. 1984. Panel Data. In Handbook of Econometrics, ed. Griliches and Intriligator. Vol. 2 Amsterdam: North-Holland.

Dex, S, H Joshi and S Macran. 1999. "Women's Employment Transitions Around Childbearing." The Oxford Bulletin of Economics and Statistics 60(1):79-97.

Elliott, J and D Egerton. 2001. "The influence of qualifications on women's work histories, employment status and earnings at age 33." European Sociological Review 17(2):145-168.

Fagan, C and J O'Reilly. 1998. Conceptualising Part-time Work: The Value of an Integrated Comparative Perspective. In Part-Time Prospects: An International Comparison of Parttime Work in Europe, North America and the Pacific Rim, ed. C Fagan and J O'Reilly. London, Routledge pp. 1-32.

Geweke, J. 1991. "Efficient simulation from the multivariate normal and Student-T distributions subject to linear constraints." Computer Sciencesand Statistics Proceedings of the 23rd Symposium on the Interface pp. 571-578.

Ginn, J, Arber S Brannen J Dale A Dex S Elais P Moss P Pahl J Roberts C Rubery J. 1996. "Feminist Fallacies: A Reply to Hakim on Women's Employment." British Journal of Sociology 47(1):167-74.

Greenhalgh, C. 1980. "Male-Female Wage Differentials in Great Britain: Is Marriage an Equal Opportunity?" Economic Journal 90(363):751-75. 
Hajivassiliou, V, D McFadden and P Ruud. 1996. "Simulation of multivariate normal rectangle probabilities and their derivatives theoretical and computational results." Journal of Econometrics 72(1):85-134.

Hajivassiliou, V. and P. A. Rudd. 1994. Classical Estimation Methods for LDV Models Using Simulation. In Handbook of Econometrics, ed. C. Engle and D. McFadden. Amsterdam: North-Holland pp. 2383-41.

Hakim, C. 1998. "Developing a sociology for the twenty-first century: Preference Theory." The British Journal of Sociology 49(1):137-43.

Heckman, James J and George J Borjas. 1980. "Does Unemployment Cause Future Unemployment? Definitions, Questions and Answers from a Continuous Time Model of Heterogeneity and State Dependence." Economica 47(127):247-83.

Heckman, J. 1981. Statistical Models for Discrete Panel Data. In Structural Analysis of Discrete Data and Econometric Applications, ed. C. Manski and D McFadden. Cambridge: The MIT Press chapter 3, pp. 115-178.

Hyslop, D. 1999. "State Dependence, Serial Correlation and Heterogeneity in Intertemporal Labor Force Participation of Married Women." Econometrica 67(6):1255-1294.

Martin, J and C Roberts. 1984. "Women and Employment: a Lifetime Perspective." London: HMSO.

McRae, S. 1993. "Returning to work after childbirth: opportunities and inequalities." European Sociological Review 9(2):125-137.

Miller, P. 1987. "The Wage Effect of the Occupational Segregation of Women in Britain." Economic Journal 97(388):885-96. 
Mincer, J and S Polachek. 1974. "Family Investments in Human Capital: Earnings of Women." The Journal of Political Economy 82(2):76-108.

Morgan, G and D Knights. 1991. "Gendering Jobs: Corporate Strategy, Managerial Control and the Dynamics of Job Segregation." Work, Employment and Society 5(2):181-200.

Pudney, S and M Shields. 2000. "Gender, race, pay and promotion in the British nursing profession: estimation of a generalized ordered probit model." Journal of Applied Econometrics $15(4): 367-399$.

Standard Occupational Classification: Volume 1. 1990. London: HMSO.

Stewart, M and C Greenhalgh. 1984. "Work History Patterns and the Occupational Attainment of Women." Economic Journal 94(127):493-519. 


\section{Appendix: Description of Data}

\begin{tabular}{|c|c|}
\hline VARIABLE & DEFINITION \\
\hline AGE & Age in years. \\
\hline AGE0 & Age, in years, at which the individual left full-time education. \\
\hline DEGREE & $\begin{array}{l}\text { Indicator variable taking the value } 1 \text { is the individual has qualifications equivalent } \\
\text { to a first degree or higher, or professional qualifications such accounting or teaching }\end{array}$ \\
\hline & qualifications, and zero otherwise. \\
\hline TECHQUAL & $\begin{array}{l}\text { Indicator variable taking the value } 1 \text { if the individual has technical qualifications such } \\
\text { as a HND, HNC, OND, ONC or BTEC. }\end{array}$ \\
\hline CHILD1215 & Number of children aged between 12 and 16 years in the household. \\
\hline CHILD511 & Number of children aged between 5 and 11 years in the household. \\
\hline CHILD04 & Number of children aged under 5 years in the household. \\
\hline COHABIT & Indicator variable taking the value 1 if the individual is cohabiting and zero otherwise. \\
\hline $\mathrm{FTH}_{i, j}$ & $\begin{array}{l}\text { Indicator variable taking the value } 1 \text { if the individual is in a full-time, high occupation } \\
\text { job at time } j \text {, and zero otherwise. }\end{array}$ \\
\hline $\mathrm{FTL}_{i, j}$ & $\begin{array}{l}\text { Indicator variable taking the value } 1 \text { if the individual is in a full-time, low occupation } \\
\text { job at time } j \text {, and zero otherwise. }\end{array}$ \\
\hline $\mathrm{PTH}_{i, j}$ & $\begin{array}{l}\text { Indicator variable taking the value } 1 \text { if the individual is in a part-time, high occupation } \\
\text { job at time } j, \text { and zero otherwise. }\end{array}$ \\
\hline $\mathrm{PTL}_{i, j}$ & $\begin{array}{l}\text { Indicator variable taking the value } 1 \text { if the individual is in a part-time, low occupation } \\
\text { job at time } j \text {, and zero otherwise. }\end{array}$ \\
\hline
\end{tabular}

Table 6: Definitions of NCDS variables. 


\begin{tabular}{|c|c|}
\hline $8: 3: 3$ & |: $: 1: 3$ \\
\hline 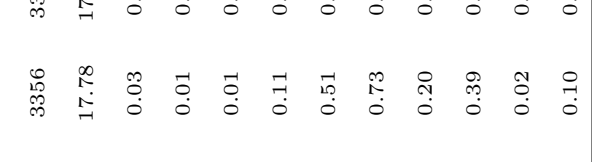 & : \\
\hline 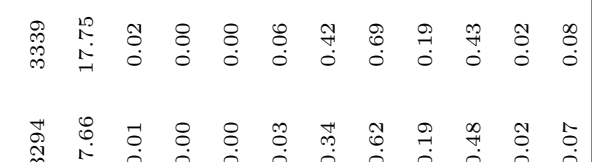 & \\
\hline Insazazas & $=18$ \\
\hline & \\
\hline 45 & \\
\hline 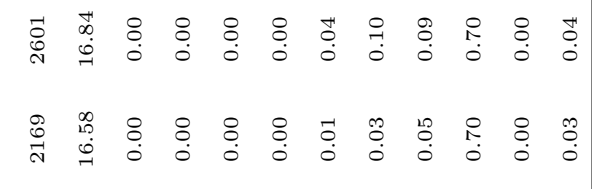 & 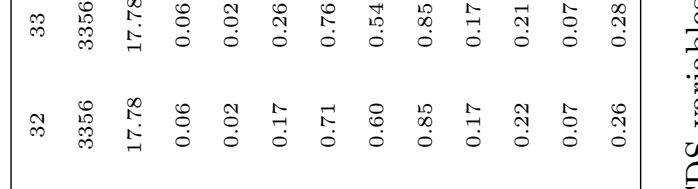 \\
\hline 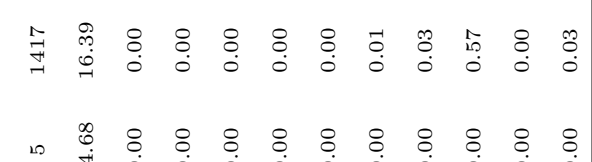 & 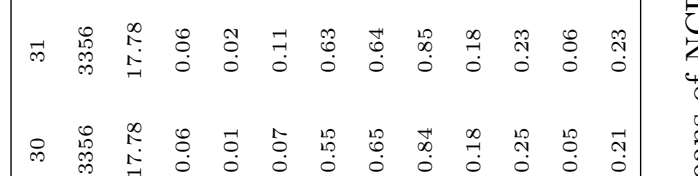 \\
\hline "1) & \\
\hline MIIIII & II \\
\hline
\end{tabular}

